\title{
Presentación Dosier Educación intercultural en Chile y América Latina
}

La presente publicación presenta una serie de propuestas y trabajos emanados de un interés y aspiración nacional e internacional por promover y consolidar los estudios sobre interculturalidad en Chile y América Latina. El incremento del movimiento de personas dentro de la región ha convocado el interés por generar conocimiento a través de estudios e investigaciones para develar y problematizar las múltiples dimensiones de transformación social y de los procesos de inserción en otras culturas.

Este dosier es la concreción de reflexiones, acciones y relatos de académicas y académicos sobre los escenarios emergentes que se han generado en los últimos 30 años con la movilidad entre fronteras de todos los países del mundo, para la búsqueda de mejores condiciones de vida, lo que ha dado paso a una población diversa y compuesta por distintas culturas que comparten un mismo territorio.

En el caso de los movimientos sociales en Chile y América Latina, en general, las categorías de análisis utilizadas para su comprensión son etnocéntricas, en las que se transfieren categorías propias de una cultura a otra dificultando la comprensión de las particularidades de otros pueblos. De esta forma, se utilizan categorías genéricas como religión, política, economía, entre otras.
En la primera parte del dosier "Educación intercultural en Chile y América Latina", se presenta el artículo "Las infancias transnacionales desde las perspectivas postcolonial y decolonial" del autor Manfred Liebel. La publicación compila los resultados de investigaciones relacionadas con la infancia, así como sus ideas y conceptos en Europa desde finales de la Edad Media, cuestionando el modelo europeo de infancia visto como la forma más elevada de civilización y que se utilice como un criterio globaly transnacional para evaluar otras formas de infancias alrededor del mundo, puesto que dicho modelo se impuso a través de un proceso (post)colonial-imperial.

En la "Migración boliviana y escuela secundaria en Argentina: reflexiones en clave intercultural" de Gabriela Novaro, se presenta el trabajo investigativo y la reflexión de la autora, respecto a las políticas educativas argentinas en los últimos años y los múltiples desafíos que se plantean a la escuela, principalmente en el ámbito de la interculturalidad, escenario obligado en el contexto migratorio actual. Producto de esta indagación, la autora realiza una fuerte crítica a la escolarización de los jóvenes migrantes y descendientes por ser descontextualizada a sus particularidades y a las voces y experiencias de padres, referentes comunitarios, jóvenes y docentes. En particular discurre sobre los avances 
y límites de las escuelas secundarias de la localidad para trabajar con la condición transnacional de vida de los jóvenes y dar lugar a la apuesta simultanea de ellos y sus familias por mantener su distintividad como colectivo e incluirse en la sociedad argentina.

En "Una aproximación a las relaciones interculturales en escuelas secundarias de Villa Lugano, a partir del análisis de las representaciones sociales hacia población de origen boliviano en Buenos Aires (2015-2018)" de Gisele Kleidermacher y Darío Lanzetta, se profundizan en las relaciones interculturales que se producen en las aulas de escuelas de educación media estatales de la Ciudad Autónoma de Buenos Aires. Se exponen los resultados relacionados con las representaciones sociales de alumnos de 14 a 16 años que asisten a estas escuelas. En un escenario con presencia de diversas nacionalidades migrantes que comparten y conviven en un mismo territorio, así como los vínculos que se generan en la escuela. Para finalmente, problematizar el rol de la escuela en el tratamiento de la discriminación y la migración. El artículo presenta los resultados del instrumento aplicado "cuestionario" a este grupo etario, construyendo categorías de análisis de acuerdo con la teoría fundamentada, entendiendo que estas representaciones dificultan la construcción de relaciones interculturales intra-áulicas.

En "Ciudadanía Cultural en estudiantes de Escuelas Normales públicas de Ciudad de México", Hilda Aguayo Rousell expone los resultados de la investigación en torno a las actitudes y manifestaciones de aceptación, rechazo y/o discriminación frente a las poblaciones indígenas en estudiantes de 5 escuelas normales públicas de la Ciudad de México, como rasgos de su ciudadanía cultural. Para obtener los resultados de esta investigación, se construyen redes semánticas, utilizando 3 categorías: aceptación, discriminación y denuncia. Tales resultados muestran que, no obstante se señala reiteradamente que no hay discriminación hacia estas comunidades, las expresiones cotidianas muestran lo contrario. Se observa la persistencia de formas de socialización a pesar que se presentan asignaturas curriculares específicas sobre Educación Ciudadana y un número menor de instituciones normalistas enfatizan la formación de los docentes como ciudadanos, soslayando la importancia de esta dimensión en un país como México, que intenta avanzar hacia la democracia y el desarrollo personal, ético, moral y social del futuro profesor o profesora.

En "Representaciones sociales docentes y neurociencias educativas: posibles vínculos para el caso argentino en torno al aula intercultural", Paula Luciana Buratovich, Anahí González y Romina Tavernelli exhiben los resultados de una investigación en curso, enmarcada en una perspectiva sociológica que se focaliza en el análisis de las representaciones sociales de miembros de escuelas primarias y secundarias del área metropolitana de Buenos Aires y cómo se articulan con los discursos provenientes de las neurociencias educativas. Es decir, los modos en que se ges- 
tiona la interculturalidad en la escuela respecto a la presencia y el desempeño escolar de niños y niñas migrantes, y cómo estas representaciones se instauran como nuevas modalidades de gestión, disciplinamiento y control social de la diversidad en la institución escolar, coadyuvando de esta forma en la reproducción de procesos de exclusión de poblaciones en situación de vulnerabilidad, tales como niños, niñas y adolescentes de origen migrante.

En "Migrantes, madres y alumnas: las diversas presencias de mujeres bolivianas en escuelas de Córdoba (Argentina)", María Florencia Maggi y Carina Inés Trabalón sintetizan los resultados de una investigación en que se analizan las representaciones sobre las mujeres migrantes bolivianas al interior de los espacios escolares del barrio: un primario de adultos del cual son alumnas, un jardín de infantes y una escuela primaria de niños/as a los cuales asisten sus hijos/ as. Se recuperan sus historias de vida a partir de las experiencias de mujeres de origen boliviano en torno a las relaciones que establecen en diferentes espacios escolares de un barrio periférico de la ciudad de Córdoba (Argentina)y la configuración de sus procesos identitarios a partir de las categorías "alumnas" y "madres". Para ello, desde un enfoque cualitativo, se analizan las características de los procesos migratorios en la ciudad de Córdoba (y en el barrio), la dinámica particular que caracteriza a las diferentes instituciones escolares y los aspectos relativos a la condición socioeconómica del barrio en general y de la población migrante en particular.
En "La educación intercultural en un contexto de desfinanciamiento en la provincia de Buenos Aires, Argentina", Emilio Tévez y Sofía Dueñas Díaz plantean el desafío que representa asumir las particularidades de la perspectiva intercultural en la actualidad, en tanto política educativa en la provincia de Buenos Aires, y las formas en que es apropiada por estudiantes de profesorado de nivel primario en un contexto de crisis económica y recorte presupuestario. El abordaje metodológico se realiza desde un enfoque etnográfico a través de la observación participante, la entrevista y relevamiento de fuentes documentales en un Instituto Superior de Formación Docente de una localidad del centro de la Provincia de Buenos Aires (Argentina). El resultado obtenido hasta aquí devela la continuidad de la perspectiva intercultural como eje organizativo de la enseñanza escolar y, al mismo tiempo, el desfinanciamiento de los programas y políticas para su implementación. A partir del análisis realizado, a modo de conclusión, se plantea que pese al contexto de desfinanciamiento, los conflictos sociales, los procesos históricos y las experiencias cotidianas de las estudiantes se orientan a reconocer un mundo complejo y diverso. Por ello, se considera necesaria y relevante la implementación de programas orientados a la incorporación de la perspectiva intercultural en la experiencia cotidiana del trabajo docente.

En "Educación intercultural en el contexto Latinoamericano. Una mirada a la Etnomatemática”, Elia Calderón Leyton discurre teóricamente sobre los factores y estrategias para el análisis de 
la interculturalidad y la pedagogía intercultural etnomatemática, destacándose su incorporación en algunas líneas fundantes en Latinoamérica para dar respuesta a la demanda en educación intercultural que hace referencia a los pueblos indígenas y afrodescendientes en Latinoamérica. De acuerdo con el análisis de los datos obtenidos, el problema que se discute es la confrontación de saberes y conocimientos de personas pertenecientes a esferas culturales diferentes, en que se transfieren categorías propias de una cultura a otra dificultando la comprensión de las particularidades de otros pueblos, impidiéndoles su desarrollo efectivo en la construcción cultural de una sociedad con mayor equidad para todos sus ciudadanos y ciudadanas.

Esta breve reseña con variadas y relevantes experiencias que se despliegan en este dosier de interculturalidad y educación, presentar un texto que recopila diversas experiencias que permiten el levantamiento de información y los análisis originales que la componen con rigurosidad científica, los que no agotan la riqueza y tampoco las proyecciones de la temática abordada. Esperamos que esta publicación sea un aporte para los estudiosos y estudiosas de la interculturalidad en educación.

Dra. Raquel Flores Bernal Editora Dosier Universidad Bernardo O’Higgins Santiago, Agosto de 2019 